\title{
EHEALTH EUROCAMPUS PROJECT: PREPARING INNOVATIVE ICT PROFESSIONALS
}

\author{
N. Castell ${ }^{1}$, J. Lobo ${ }^{2}$, E. Insa ${ }^{3}$, R. Picking ${ }^{4}$, Y. González ${ }^{5}$, S. Abdelaziz ${ }^{6}$, B.

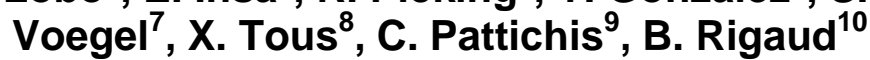 \\ ${ }^{1}$ Universitat Politècnica de Catalunya (SPAIN) \\ ${ }^{2}$ Eurorégion Pyrénées-Méditerranée GECT (FRANCE) \\ ${ }^{3}$ Campus Docent Sant Joan de Déu (SPAIN) \\ ${ }^{4}$ Glyndwr University (UNITED KINGDOM) \\ ${ }^{5}$ Universitat de les Illes Balears (SPAIN) \\ ${ }^{6}$ Université de Montpellier (FRANCE) \\ ${ }^{7}$ Hochschule Ulm (GERMANY) \\ ${ }^{8}$ Fundació Bit (SPAIN) \\ ${ }^{9}$ University of Cyprus (CYPRUS) \\ ${ }^{10}$ Institut National Universitaire Champollion (FRANCE) \\ castell@cs.upc.edu, joao.lobo@euroregio-epm.eu, einsa@santjoandedeu.edu.es, \\ r.picking@glyndwr.ac.uk,yolanda.gonzalez@uib.es, salih.abdelaziz@lirmm.fr,voegel@hs- \\ ulm.de,xtous@fundaciobit.org, pattichi@ucy.ac.cy, bernard.rigaud@univ-jfc.fr
}

\begin{abstract}
The eHealth Eurocampus project, an EU-funded project, aims at preparing innovative professionals able to cope with the challenge of fostering a spirit of innovation in eHealth in Europe as the way forward to ensure better health and better and safer care. The main objectives of the eHealth Eurocampus are improving the relevance and quality of higher education in the field of ICT applications for health, and fostering employability through curricula adaptation to labour market needs and the development of entrepreneurship skills. In the frame of this project we are developing course materials, and implementing new and innovative teaching methods that are tested through joint learning activities (summer schools), which will be used later on in different master courses. The project includes the organization of training seminars to exchange good practices and knowledge among teachers and researchers. The eHealth Eurocampus consortium includes 8 higher education institutions, a regional centre of technological development and entrepreneurship promotion, and a European Grouping of Territorial Cooperation. The partnership represents different European health management systems, from 5 European countries.
\end{abstract}

Keywords: EHealth education, multidisciplinary education, international cooperation, innovation in education, ICT for health.

\section{INTRODUCTION}

eHealth supports services addressing wellness and diseases management (prevention, diagnosis, therapy, rehabilitation, long-term care, telemedicine) and activities facilitating the supply of healthrelated goods and services, including the provision of health-related collaboration platforms, which depend on IT infrastructure (electronic health record, picture archiving and communication systems, ePrescriptions, health cards, health portals, clinical information systems).

In 2015 the Eurorégion Pyrénées-Méditerranée conducted a study about the state of the art on European university programs related to eHealth [1]. The survey stressed the importance of higher education programs on the growing eHealth sector, the topics that must be covered (some of them not included in any program at that time), and the interdisciplinarity of the sector. One of the general recommendations was to mix various student profiles: nurses, physicians, IT professionals, who have their own background and vision. This mix should help them to cope with understanding a variety of issues, systems, technological barriers... The eHealth Eurocampus project was designed taking into account the findings and the recommendations of this survey.

The eHealth Eurocampus (ehealtheurocampus.eu) is an EU-funded Erasmus+ Strategic Partnership for higher education (September-2016 / August-2019) which aims at preparing professionals able to cope with the challenge of "fostering a spirit of innovation in eHealth in Europe as the way forward to 
ensure better health and better and safer care for EU citizens, a more skilled workforce, more efficient and sustainable health and care systems, new business opportunities" (EC eHealth Action Plan 20122020). The project fosters employability through the promotion of entrepreneurship and by equipping students with basic skills needed by the labour market: Europe has a number of large companies specialised in eHealth solutions, especially on telemedicine, home care and clinical information systems in the primary healthcare sector, as well as more than 5000 SMEs active in various subsectors of eHealth.

In the frame of this project we are developing course materials, and implementing new and innovative teaching methods that are tested through joint learning activities (summer schools), which will be used later on in different master courses. The project includes the organization of training seminars to exchange good practices and knowledge among teachers and researchers. The project beneficiaries will be students and staff, which will receive special training, as well as patients in general, in particular elderly people and people with physical and cognitive disabilities, who will benefit from the outcomes of the research conducted within the partnership.

The main objectives of the eHealth Eurocampus are:

- Improving the RELEVANCE of higher education in the field of information and communication technologies applications for health (eHealth);

- Enhancing the QUALITY of eHealth higher education through mobility and transnational cooperation;

- Fostering EMPLOYABILITY through curricula adaptation to labour market needs, taking into account the diversity of the European health systems;

- Providing skills of ENTREPRENEURSHIP for students, especially those adapted to the eHealth sector.

Through the eHealth Eurocampus project, joint production of innovative teaching material is boosted by a partnership with different technical and academic expertise and diverse health systems backgrounds; this material is tested in the Living Labs which are the intensive study programmes, before being disseminated and introduced in IT studies curricula. The eHealth sector itself, as acknowledged by the European Commission, has a potential of innovation, and the eHealth Eurocampus will be dealing with matters that are real challenges nowadays, e.g. handling a growing aging population and coping with cognitive disabilities, an issue that has still to be dealt with properly.

The eHealth Eurocampus is a truly European project in which, for the first time, the use of ICT in healthcare is dealt from very different perspectives and disciplines: education, entrepreneurship, assistive healthcare medicine, medical robotics, medical imaging, privacy and data security, ethics and law, etc. Moreover, one of its main goals is to create an original eHealth teaching-learning space where university professors, students, researchers, and clinicians are able to share their experiences and knowledge with the aim of improving the skills of graduates with the aim of improving their employability. The experience until now is very valuable and successful.

\section{THE CONSORTIUM}

The eHealth Eurocampus has a truly European perspective, as it develops teaching materials in collaboration between universities and allows for testing them on a highly diverse set of students. The project partners (Fig. 1) include 8 higher education institutions, which represent 7 IT schools (Barcelona School of Informatics - UPC, Polytechnic School of the Balearic Islands, Polytech Engineer School of Montpellier, ISIS Engineering School of Castres, Glyndwr University of Wales, Hochschule Ulm, and the Department of Computer Science of the University of Cyprus) and 3 medical schools (Faculty of Nursing and Physiotherapy of the Balearic Islands, Medical School of Cyprus, Sant Joan de Déu University School of Nursing - Barcelona), a regional centre of technological development and entrepreneurship promotion (Bit Foundation of Mallorca), and a European Grouping of Territorial Cooperation (EGTC Pyrenees-Mediterranean).

Furthermore, the partnership represents the five European health management systems identified by the Committee of the Regions [2]: decentralized (Spain), partially decentralized (Germany), operatively decentralized (United Kingdom), centralized but structured (France) and centralized (Cyprus). This variety, which is present at the very heart of the consortium, will help to form professionals aware of 
the European diversity in this area and prepared to adapt themselves to different environments and to find jobs outside their own country more easily.

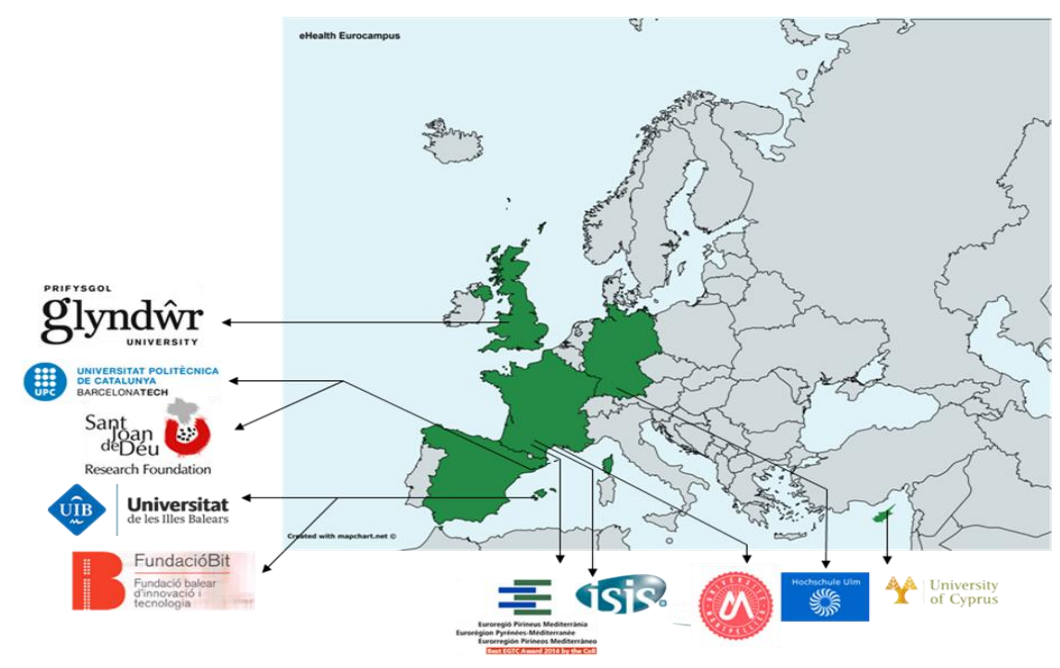

Figure 1. eHealth Eurocampus consortium

\section{METHODOLOGY}

The eHealth Eurocampus includes three annual cycles. Each year:

- Teaching material is developed and used/tested during the Intensive Study Program for students; then, it is evaluated and adapted to be used in master courses. The learning activities will be centred on different topics: entrepreneurship, longer independent life, physical and cognitive disabilities; all of them will include social, technical and business issues. The idea is not only to use the same material each year, but to redevelop it based on previous experience. Content and learning goals can be adjusted and modules from previous years remain available.

- Teachers have had the possibility to participate in Training Events on didactics and on innovative methods and tools (second and third year). These training sessions have been prepared by the organization in charge of the activity and the remaining participating organizations.

The website of the project (ehealtheurocampus.eu) enables to share reflections within the partnership, but also with people from outside the consortium.

The results of the project will reach different target audiences, including students, teachers, health professionals and decision makers. Everything is stored in a form that makes the material useful for people from outside organizations, both during the project and after it.

The closing seminar of the project, to be held in Barcelona on July 2019, will contribute to the dissemination of the results. All the material will be made publicly available and will be a support for studies at different levels, especially integrated in master degree courses.

\section{ACTIVITIES AND RESULTS}

The so-called intellectual outputs of the eHealth Eurocampus project are the course materials for 5 topics:

- I2eH: a module on innovation and entrepreneurship (finished)

- IT-LIL: a module on IT for a Longer Independent Life (quite finished)

- mHealth: a module on eHealth Applications and Tools (quite finished) 
- RHC: a module on Robotics for Healthcare (on going)

- GMI: a module on Graphics and Medical Imaging (on going)

As we mention in the previous section, the developed teaching material is used/tested during an Intensive Study Program for students in summer school format. The material of the module is revised taking into account the experience of the summer school, and after a final revision it is ready for a public use.

\section{Intellectual outputs}

The I2eH course introduces students to entrepreneurship, giving positive images of businessmen, and encouraging them to creation and innovation through "action training" approaches.

It has the objectives of a) contributing to the emergence of young businessmen/businesswomen giving them the opportunity to test their entrepreneurship potentialities; b) providing students with knowledge useful for entrepreneurship, key know-how to create business, and personal conducts required to the success of the entrepreneurial process; and c) initiating students to the specificities of the different European eHealth ecosystems.

The overall aim of the IT-LIL course is to develop students' skills in designing software applications to support a longer independent life for their users.

Once a student has completed this module, he/she will possess the knowledge and skills to produce high-quality prototype designs that can subsequently be tested with users in a controlled environment, such as a usability laboratory. Students will also gain the appropriate skills to design field testing (in real-world environments).

The aim of the mHealth course is to enable participants to develop applications for mobile devices (tablets, smartphones,...).

The students will learn how to use the integrated sensor elements of the mobile devices (e.g. the connecting gyroscope sensor and the possibilities of communicating messages via email, SMS, Web Services) and the subsequent analysis of their content (e.g. using business intelligence techniques). Additionally, students will learn about interfaces to other electronic devices in the eHealth area. Privacy and data security as well as ethics and juridical aspects are included in this course.

The RHC course aims at providing skills and knowledge on robotics and their application in healthcare. The main goals of the course are the introduction to the methodological bases of robot modelling and control as well as the analysis of the medical requirements of robotics in each health area.

By the end of the training, the student should have skills and knowledge to consider the human factors as part of the inputs to the project to develop, to analyze a problem and identify the project requirements, to select the adequate control strategy for each robot project, to conceive a project as a whole, and to develop projects in the field of systems engineering, control and robotics for healthcare.

The GMI course is centred on the development of skills (graphics) that make students operative regarding health applications to cope with physical and cognitive disabilities.

The objective of this module is to cover the basic knowhow, and technologies involved in the development of virtual environments and serious games immersed with medical image and video content. Once the student has completed this module he/she will be able to analyze a problem in the medical domain, extract the needs and requirements and proceed with the design, development, and implementation of the virtual environment of serious game needed.

\section{Summer Schools}

The participants of the summer schools are students from the partner institutions, mixing engineers with health students. This interdisciplinarity is a challenge and force to look for different learning/teaching approaches. Summer Schools are used as a testbed of materials and innovative teaching methodologies. 
The first module on innovation and entrepreneurship was tested in the summer school of the first year of the project (June, 26 / July, 7 - 2017). It was organized by ISIS Engineering School and collocated with the "Université d'été de la santé" that takes place every July in Castres. The participants were 42 students of the academic institutions of the consortium and 7 professors. The experience was very good.

The module on IT for a Longer Independent Life was combined and tested with the module on eHealth Applications and Tools during the summer school of the second year of the project. It took place in Wrexham (June, 25 / July, $6-2018$ ) and it was organized by Glyndwr University of Wales. The participants were 53 students of the academic institutions of the consortium and 13 professors. The experience again was very good, and even more multidisciplinary due to the collaboration of theatre students playing the role of users [3].

The module on Robotics for healthcare and the module on Graphics and Medical Imaging will be tested during the last summer school that will take place in Barcelona (July, 1-12 , 2019), organized by the Barcelona School of Informatics.

\section{Training Seminars}

During the first two years of the project, we have organized two internal seminars. These seminars were oriented to the teachers of the academic institutions of the consortium. The goal is to exchange good practices and knowledge among teachers and researchers, discussing about didactics and about innovative methods and tools.

The topic of the first seminar was "eHealth Teaching Challenges". It was organized by Polytech Engineer School of Montpellier, on October 2017.

The second seminar was organized by Polytechnic School of the Balearic Islands. It took place in Palma de Mallorca on November 2018. The topic was "Accessibility, Inclusion, and Rehabilitation"

\section{Multiplier event}

After the last summer school, in July 2019, the results of the project will be presented during an open two-day seminar in Barcelona. The agenda of this event is under preparation.

\section{CONCLUSIONS}

The eHealth Eurocampus project supports the development of innovative teaching material and activities that will improve the relevance and quality of higher education in the field of eHealth by adapting curricula to labour market needs, while providing students with skills of entrepreneurship through innovative and learner-centred methods.

We consider very successful the cycle methodology applied. The material is developed in collaboration of the partners more experts on the topics, then it is tested during a summer school, and finally reviewed to create the public version.

Dealing with the multidisciplinary profiles of the participants (both students and teachers) on the summer schools is a challenge, and at the same time a very enriching and fruitful experience. This aspect has been really appreciated for all the participants.

The internal training seminars have been very successful. They provided a practical way to exchange good practices, and knowledge. Moreover they facilitate the exploration of additional paths of collaboration among the partners of the consortium.

\section{ACKNOWLEDGEMENTS}

This project is carried out with the financial support from EU commission under the Erasmus+ Program, KA2 - Cooperation for Innovation and the Exchange of Good Practices, Strategic Partnership for higher education (ref. 2016-1-FR01-KA203-023932). 


\section{REFERENCES}

[1] Mapping Consulting, "eHealth Higher Education survey", 2016. Retrieved from http://www.euroregio.eu/sites/default/files/ehealth_education_survey.pdf

[2] Progress Consulting S.r.I. and Living Prospects Ltd., "The management of health systems in the EU Member States - The role of local and regional authorities", 2012. Retrieved from https://cor.europa.eu/es/engage/studies?from $=01 / 01 / 2012 \&$ to $=01 / 01 / 2013$

[3] R. Picking, A. Graells, E. Insa and I. Salinas, "An Evaluation of student perceptions of the effectiveness of multidisciplinary teaching and learning in eHealth", in INTED-2019. 